\title{
Surgical treatment of congenital mitral stenosis: Medium-term results
}

\author{
A evolução a médio prazo da correção cirúrgica da estenose mitral congênita
}

Fernando A. ATIK, Brian W. DUNCAN, Geoffrey L. ROSENTHAL, Isamu KAWASE, Raja JOSHI, Roger B. B. MEE

RBCCV 44205-651

\begin{abstract}
Objective: For a cohort of patients with congenital mitral stenosis (CMS), to determine: patient outcomes, predictors of valve repairability and predictors of durability of valve repair.

Methods: From 1989 and 2002, 23 patients underwent surgical treatment of CMS, excluding those with common atrioventricular canal, and univentricular forms. The median age at operation was 15.5 months (range 2-204), and the median body weight was $11 \mathrm{Kg}$ (range 4.5-51.6). Seventeen patients $(73.9 \%)$ had associated anomalies, including Shone's complex in nine $(39.1 \%)$ and pulmonary hypertension in 14 $(60.9 \%)$. Mitral stenosis was severe in 14 patients $(60.9 \%)$ and moderate in the remaining (median trans-mitral gradient of $16 \mathrm{mmHg}$, range 8.5-32). Mitral valve repair was performed in 18 patients $(\mathbf{7 8 . 3 \%})$, and valve replacement in five $(\mathbf{2 1 . 7 \% )}$ ). Repair techniques included papillary muscle splitting $(\mathrm{n}=10)$, excision of supravalvular ring $(n=9)$ and commissurotomy $(\mathrm{n}=8)$. Twelve patients $(\mathbf{5 2 . 2 \%})$ required associated procedures.

Results: There were no early and late deaths at a mean follow-up of $58.5 \pm 46.7$ months (range 1-156). Mean hospital
\end{abstract}

stay was $12.7 \pm 8.2$ days. There were no significant factors associated with unsuccessful valve repair. Actuarial freedom from reoperation at five years was $67.1 \%$ (CI 95\%: $56.8 \%$ to

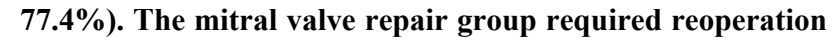
in eight patients (44.4\%) (two early and six late), as opposed to one $(20 \%)$ in the replacement group. The presence of preoperative pulmonary hypertension was significantly related $(p<0.005)$ to higher reoperation rates. All but two the followed patients are presently in functional class $I$ and the echocardiography has shown less than $2+$ mitral stenosis and/or regurgitation.

Conclusion: Reoperations were the most important cause of morbidity at the medium-term follow-up of CMS. Preoperative pulmonary hypertension may predict the need for reoperation after mitral valve repair, which is the procedure of choice in CMS.

Descriptors: Mitral valve stenosis, congenital. Mitral valve stenosis, surgery. Mitral valve, abnormalities. Heart defects, congenital, surgery

Center of Pediatric and Congenital Heart Diseases, The Cleveland

Clinic Foundation, Cleveland, OH, USA

Address for correspondence:

Fernando Atik

13200 Fairhill Rd apt.10 Shaker Heights, OH 44120 USA

Article received on April, 2003 E-mail: atik@uolcom.br 


\section{Resumo}

Objetivo: Analisar a evolução de pacientes portadores de estenose mitral congênita (EmiC) submetidos a tratamento cirúrgico, buscando estudar os fatores desfavoráveis da plastia valvar e os seus marcadores de durabilidade.

Método: De 1989 a 2002, 23 pacientes foram submetidos a tratamento cirúrgico da $\mathbf{E m i C}$, excluindo aqueles com defeito do septo atrioventricular, e formas univentriculares. A idade mediana foi de 15,5 meses (variação de 2 a 204), e o peso mediano foi de $11 \mathrm{~kg}$ (variação 4,5 a $51,6 \mathrm{~kg}$ ). Anomalias associadas estiveram presentes em $17(73,9 \%)$, complexo de Shone em nove $(39,1 \%)$ e hipertensão pulmonar em 14 $(60,9 \%)$. A estenose mitral era grave em $14(60,9 \%)$ pacientes, e moderada no restante (gradiente transmitral mediano de $16 \mathrm{mmHg}$, variação 8,5 a 32). A plastia valvar foi realizada em $18(78,3 \%)$ pacientes e a troca em cinco $(21,7 \%)$. As técnicas de plastia incluiram a papilarotomia $(n=10)$, ressecção de membrana supravalvar $(n=9)$ e comissurotomia $(n=8)$. Doze $(52,2 \%)$ pacientes requereram procedimentos associados.

Resultados: Não houve óbitos precoces ou tardios num seguimento médio foi de $58,5 \pm 46,7$ meses (variação 1 a 156 meses). O tempo médio de hospitalização foi de $12,7 \pm 8,2$

\section{INTRODUCTION}

Congenital mitral stenosis (CMS) is a rare cardiac malformation. The estimated prevalence is 4 in each 1000 children diagnosed with congenital heart disease [1]. CMS is frequently associated with other cardiac anomalies [2], especially left heart obstructive lesions [3].

Despite great advances in the reparative techniques of congenital mitral regurgitation [4], the surgical treatment of CMS is still a challenge, particularly in neonates and small infants. In this population, there is a high probability of valve replacement due to unfavorable anatomical characteristics, such as small annulus size and abnormalities in the papillary muscles. The well-known lack of an ideal valve substitute aggravates this problem.

Surgical mortality of CMS has reduced dramatically over the last decades, a result of several improvements in pediatric cardiac surgery and the incorporation of intraoperative transesophageal echocardiography[5]. Nevertheless, the best treatment plan for CMS has not yet been defined because of two main reasons: 1) wide range of anatomical forms and 2) relatively small numbers of patients surgically treated at any single institution.

Traditionally, surgical treatment in neonates carries a higher risk. Therefore, the indication for surgery should be postponed until there are signs of progressive pulmonary venous congestion or onset of pulmonary hypertension. The presence of associated anomalies that require neonatal intervention usually is another indication. dias. Não foram encontrados fatores de risco associados a insucesso da plastia valvar. A curva atuarial livre de reoperações em cinco anos foi de 67,1\% (IC 95\%: 56,8\% a $\mathbf{7 7 , 4 \% ) .} O$ grupo submetido a plastia valvar necessitou de reoperação em oito $(44,4 \%)$ pacientes, sendo dois precoces e seis tardios, comparados com uma (20\%) reoperação no grupo submetido à troca valvar. A presença de hipertensão pulmonar no pré-operatório esteve relacionada significativamente $(\mathbf{p}<0,005)$ a maiores taxas de reoperação. Todos os pacientes, exceto dois, encontram-se em classe funcional I da NYHA e o ecocardiograma mostra no máximo insuficiência e/ou estenose mitral leve.

Conclusões: As reoperações foram o maior fator de morbidade no seguimento a médio prazo e a hipertensão pulmonar pôde ser considerada o fator adverso de durabilidade da plastia mitral, a qual foi o tratamento de escolha para a estenose mitral congênita.

Descritores: Estenose da valva mitral, congênito. Estenose da valva mitral, cirurgia. Valva mitral, anormalidades. Cardiopatias congênitas, cirurgia.

The aim of this study is to determine the outcomes, predictors of valve repairability and predictors of durability of valve repair in the treatment of congenital mitral stenosis.

\section{METHOD}

From January 1989 through December 2002, 23 patients underwent surgical treatment of congenital mitral stenosis. All available data on hospital charts regarding preoperative, surgery and postoperative periods were analyzed retrospectively. The follow-up was obtained through periodic consultations with echocardiographic assessment in our service, as well as through reports from other pediatric cardiology centers or family contacts.

Exclusion criteria included patients with common atrioventricular canal, single ventricle, hypoplastic left heart syndrome, congenitally corrected transposition of great arteries, predominantly congenital mitral regurgitation and acquired mitral stenosis.

Preoperative characteristics are represented in Table 1. There were 13 boys $(56.5 \%$ ), with a median age of 15.5 months (range 2-204), and median body weight of $11 \mathrm{~kg}$ (range 4.5 $51.6 \mathrm{Kg}$ ). Ten patients $(43.5 \%)$ had less than 12 months of age at the time of first operation.

Three patients $(13 \%)$ were in functional class IV (decompensated heart failure with tachypnea, tachycardia, hepatomegaly), 18 patients (78.3\%) in class III (repeated episodes of respiratory infections or compensated heart failure with anorexia and failure to thrive) and two patients 
$(8.7 \%)$ in class II (shortness of breath with occasionally respiratory infections). All patients in class IV were under mechanical ventilation and inotropic support.

Table 1. Preoperative characteristics

\begin{tabular}{lr}
\hline Males & $13(56,5 \%)$ \\
Median age (months) & 15,5 \\
Median weight $(\mathrm{kg})$ & 11 \\
Associated anomalies & $17(73,9 \%)$ \\
Shone's complex & $9(39,1 \%)$ \\
Pulmonary hypertension & $14(60,9 \%)$ \\
Inotropic support & $3(13 \%)$ \\
Severe MS & $14(60,9 \%)$ \\
Moderate/severe MR & $2(8,7 \%)$ \\
Previous operations & $11(47,8 \%)$
\end{tabular}

MS: mitral stenosis; MR: mitral regurgitation

The diagnosis was confirmed by bidimensional echocardiography, with calculation of peak and mean transmitral gradients. Mitral stenosis was severe in 14 patients $(60.9 \%)$ and moderate in nine patients $(39.1 \%)$; mean transmitral gradient was $17.9 \pm 6.2 \mathrm{mmHg}$ (range 8.5 to $32 \mathrm{mmHg}$ ). Seven patients (30.4\%) had concomitant mitral regurgitation, including five mild, one moderate and one severe; the latter related to a failed balloon valvuloplasty. The mean mitral annulus diameter was $15.9 \pm 6.6$ millimeters (range 7 to 28 ). Fourteen patients $(60.9 \%)$ had pulmonary hypertension, estimated by the right ventricular systolic pressure on echocardiography.

Cardiac catheterization was performed in seven patients (30.4\%). It offered valuable information regarding pressures and calculation of pulmonary vascular resistance in three patients with suspicion of severe pulmonary hypertension and in two patients with smallish left ventricles, serving as a guide to the feasibility of biventricular repair. In some of those patients and in the remaining, interventional cardiology was the indication of the procedure.

Associated anomalies (Table 2) were present in 17 patients (73.9\%). The most frequent one was coarctation of aorta in nine patients (39.1\%), followed by subaortic stenosis in eight patients (34.8\%).

Shone's complex occurred in nine patients (39.1\%). It was considered complete (all the four obstructive components) in only three patients, and incomplete in the remaining. Two patients had smallish left ventricles by bidimensional echocardiography, and cardiac catheterization was obtained. Despite the ventriculography having had confirmed the echocardiographic findings, in both cases the apex of the heart was formed by the left ventricle and biventricular repair was indicated.

Eleven patients $(47.8 \%)$ had been submitted to previous operations (Table 3). All patients with coarctation of the aorta were repaired previously to the mitral valve procedure.

Table 2. Associated cardiac anomalies

\begin{tabular}{lr}
\hline Associated anomalies & 17 Pacientes $(73,9 \%)$ \\
\hline Coarctation of aorta & $9(39,1)$ \\
Shone's complex & $9(39,1)$ \\
Subaortic stenosis & $8(34,8)$ \\
Bicuspid aortic valve & $4(17,4)$ \\
Supra-valvular aortic stenosis & $3(13,0)$ \\
Ventricular septal defect & $3(13,0)$ \\
Small left ventricle* & $2(8,7)$ \\
Double outlet right ventricle & $1(4,3)$ \\
Aortic regurgitation & $1(4,3)$ \\
Atrial septal defect & $1(4,3)$ \\
Patent ductus arteriosus & $1(4,3)$ \\
\hline
\end{tabular}

* the apex of the heart was not formed by the left ventricle

Table 3. Previous surgical procedures

\begin{tabular}{lr}
\hline Previous surgery & 11 pacientes $(47,8 \%)$ \\
Extended end to end aortoplasty & $8(34,8)$ \\
Subclavian flap aortoplasty [6] & $1(4,3)$ \\
Pulmonary artery banding & $2(8,7)$ \\
Subaortic resection & $1(4,3)$ \\
Resection of tricuspid valve vegetation & $1(4,3)$ \\
Thoracic duct ligation & $1(4,3)$ \\
\hline
\end{tabular}

Interventional catheterization was performed in seven patients $(30.4 \%)$. One patient underwent a neonatal mitral balloon valvuloplasty in another service. This patient had severe mitral regurgitation and major embolic stroke after the procedure. Another patient had Hammock mitral valve [2] with severe mitral stenosis associated with aortic stenosis, both of which lead to congestive heart failure in the neonatal period. This patient was submitted to balloon atrial septostomy, in order to stabilize its hemodynamic status before the surgery. Three patients with valvar aortic stenosis underwent aortic balloon valvuloplasty before the surgery that addressed the mitral valve. Two patients with residual coarctation after surgical repair were dilated in the catheterization laboratory.

Three patients (13\%) had non-cardiac associated anomalies. One had a major stroke after failed mitral balloon valvuloplasty, one had VACTERL syndrome [7] with anal atresia and neurogenic bladder. The last patient had polycystic kidney disease, status post renal transplantation, 
Medium-term results

hepatic cirrhosis and portal hypertension occurred in the follow-up.

Intraoperative transesophageal or epicardial echocardiography were performed in all patients, assessing the mechanism of mitral stenosis, and guiding the surgical plan during the procedure.

\section{Surgical technique}

The operations were carried out through conventional median sternotomy and cardiopulmonary bypass was instituted through ascending aorta and bicaval cannulation. Moderate systemic hypothermia, high pump flows and vasodilation with phenoxybenzamine were employed. Myocardial protection was achieved by intermittent antegrade cold crystalloid cardioplegia. After initiation of cardiopulmonary bypass, and the cardioplegia has been administered in the ascending aorta, the approach to the mitral valve was via interatrial septum in 16 patients $(69.6 \%)$ and via atrial groove in the remaining. The former was the choice in neonates and small infants.

Intraoperative findings were categorized according to CARPENTIER'S et al. classification [8] for congenital mitral stenosis, taking into consideration the predominant features (Table 4).

Table 4. Carpentier's classification of congenital mitral stenosis [8]

\begin{tabular}{lr}
\hline Surgical anatomy & N pacientes $(\%)$ \\
\hline Type I: Predominant valvar lesions & $7(30,4)$ \\
Annular hypoplasia & 1 \\
Supra-valvular ring & 5 \\
Double orifice & 1 \\
Type II: Predominant subvalvar lesions & $16(69,6)$ \\
Parachute mitral valve & $7^{*}$ \\
Hammock mitral valve & 1 \\
Commissure and papillary muscle fusion & 8
\end{tabular}

* 3 patients over 7 had also supra-valvular ring, but all of them were included into this category because the predominant lesion was the parachute mitral valve

Type II, with predominantly subvalvar lesions, was found in the majority of patients $(69.6 \%)$. Among those, parachute mitral valve was the main diagnosis in seven patients $(30.4 \%)$, commissure papillary fusion in eight patients (34.8\%) and Hammock mitral valve in one (4.3\%). Type I, with predominantly valvar lesions, was present in seven patients $(30.4 \%)$.

Anatomical and surgical characteristics of the 23 patients are represented in Table 5. Mitral valve repair was performed in 18 patients $(78.3 \%)$ and valve replacement in $5(21.7 \%)$.

Techniques of valve repair utilized were splitting of papillary muscles in 10 patients, resection of supra-valvular ring in nine, commissurotomy in eight, fenestration of papillary muscles in four and division of chordae in two.

Commissurotomy was performed very cautiously because usually the disease process distorts the normal anatomical landmarks. Splitting the papillary muscles in patients with CMS at subvalvar level was performed in the whole length; close to the left ventricular wall. Particularly in patients with parachute mitral valve, the single papillary muscle was divided in two or three parts, enhancing leaflet mobility during diastole.

Among eight patients with supravalvular mitral ring, half presented redundancy of the posterior wall of the left atrium requiring remodeling procedures. The resection of the ring was carefully undertaken between the mitral annulus and the endocardium, avoiding injury to the mitral valve and circumflex artery. The treatment of associated lesions in the valvar and subvalvar apparatus were employed in three patients. In those, commissurotomies, splitting or fenestration of papillary muscles, division of chordae and resection of accessory trabeculae were performed.

Mitral valve replacement was performed in five patients with mechanical prosthesis (St Jude Medical Inc., St Paul, $\mathrm{MN}$ ) with sizes ranging between 21 and 25 millimeters.

Twelve patients $(52.2 \%)$ required associated procedures (Table 5). The concomitant treatment of left ventricular outflow tract obstruction was performed in five patients. Subaortic membrane resection and myomectomy was performed in four and Ross-Konno procedure [9] in the last. The relief of subaortic stenosis was isolated in two. In the others, it was associated with aortic valvotomy, ventricular septal defect closure and aortic valve repair.

Mean cross-clamping time was $44.3 \pm 19.4$ minutes (range 19-103) and mean cardiopulmonary bypass time was $74.3 \pm$ 27.1 minutes (range 43-165). Before weaning from CPB, left atrial pressure catheters were placed. Direct pulmonary artery pressure monitoring was used in patients with pulmonary hypertension. Post-surgical transesophageal echocardiography is routinely performed. This analysis had the purpose of evaluating residual problems in the mitral valve, estimation of ventricular function and assessment of left ventricular outflow tract obstruction. None of our patients required an additional period of cardiopulmonary bypass to repair significant residual defects.

Before hospital discharge, all patients underwent bidimensional echocardiography in order to estimate eventual residual defects and pericardial effusions.

Statistical analysis was performed with software SAS version 6.12 (SAS Institute, Cary, NC). Continuous variables were expressed through median, mean and standard deviation. Fisher's exact test was used to analyze categorical variables. Univariate analysis was employed in the determination of predictors of valve repairability and 
Table 5. Anatomical and surgical demographics

\begin{tabular}{|c|c|c|c|c|c|c|c|}
\hline $\mathrm{N}$ & $\begin{array}{c}\text { Age }(\mathrm{m}) / \\
\text { Weight }(\mathrm{kg})\end{array}$ & Anatomic type & $\begin{array}{c}\text { Mean TMG } \\
(\mathrm{mmHg})\end{array}$ & Annulus (mm) & Surgical procedures & $\begin{array}{l}\text { Associated } \\
\text { procedures }\end{array}$ & Reoperations \\
\hline 1 & $2 / 4,5$ & Double orifice, Hammock & 9 & 11 & $\begin{array}{l}\text { Commissurotomy, papillary } \\
\text { muscle fenestration }\end{array}$ & - & - \\
\hline 2 & $2 / 4,5$ & Parachute & 13 & 8 & $\begin{array}{l}\text { Commissurotomy, splitting } \\
\text { papillary muscle, chordae } \\
\text { division }\end{array}$ & - & Replacement \\
\hline 3 & $4 / 7$ & $\begin{array}{l}\text { Commissure fusion, shortened chords, } \\
\text { papillary muscle hypoplasia }\end{array}$ & 15 & 17,5 & $\begin{array}{l}\text { Commissurotomy, papillary } \\
\text { muscle fenestration }\end{array}$ & Ross-Konno & Replacement \\
\hline 4 & $4 / 13$ & $\begin{array}{l}\text { Double orifice, commissure fusion, } \\
\text { thickened leaflets }\end{array}$ & 16 & 23 & $\begin{array}{l}\text { Commissurotomy, splitting } \\
\text { papillary muscle, division of } \\
\text { chords and anterior leaflet }\end{array}$ & - & $\begin{array}{l}\text { 1)Re-repair; } \\
\text { 2)Replacement }\end{array}$ \\
\hline 5 & $6 / 5$ & Shone, commissure fusion & 20 & 10 & $\begin{array}{l}\text { Commissurotomy, splitting } \\
\text { papillary muscles }\end{array}$ & - & Replacement \\
\hline 6 & $7 / 6$ & $\begin{array}{l}\text { Shone, supra-valvular ring, } \\
\text { parachute }\end{array}$ & 32 & 11 & $\begin{array}{l}\text { Resection of supra-valvular } \\
\text { ring, commissurotomy, papillary } \\
\text { muscle fenestration }\end{array}$ & VSD closure & Re-repair \\
\hline 7 & $10 / 9,4$ & $\begin{array}{l}\text { Commissure fusion, supra-valvular } \\
\text { ring, parachute }\end{array}$ & 17,9 & 18 & $\begin{array}{l}\text { Resection of supra-valvular } \\
\text { ring, splitting papillary } \\
\text { muscles, remodeling of left } \\
\text { atrium posterior wall }\end{array}$ & $\begin{array}{l}\text { Supra-valvar aortic } \\
\text { stenosis repair }\end{array}$ & - \\
\hline 8 & $10 / 9,6$ & Parachute, supra-valvular ring & 16 & 16 & $\begin{array}{l}\text { Resection of supra-valvular ring, } \\
\text { splitting papillary muscles, } \\
\text { resection of accessory trabeculae }\end{array}$ & $\begin{array}{l}\text { VSD closure, } \\
\text { subaortic resection }\end{array}$ & - \\
\hline 9 & $11 / 6,4$ & $\begin{array}{l}\text { Chordal absence, anterior leaflet } \\
\text { rupture }\end{array}$ & 15 & 19 & $\begin{array}{l}\text { Replacement: mechanical } \\
\text { prosthesis (mp) } 17 \mathrm{~mm}\end{array}$ & - & - \\
\hline 10 & $12 / 5,3$ & Shone, parachute & 16 & 10 & $\begin{array}{l}\text { Commissurotomy, splitting } \\
\text { papillary muscle }\end{array}$ & $\begin{array}{l}\text { Supra-valvar aortic } \\
\text { stenosis repair, aortic } \\
\text { valvotomy }\end{array}$ & $\begin{array}{l}\text { 1)Re-repair; } \\
\text { 2)Replacement }\end{array}$ \\
\hline 11 & $13 / 9$ & $\begin{array}{l}\text { Shone, } \\
\text { supra-valvular ring, leaflet } \\
\text { thickening }\end{array}$ & 18 & 7 & Resection of supra-valvular ring & $\begin{array}{l}\text { Aortic valvotomy, } \\
\text { subaortic resection }\end{array}$ & - \\
\hline 12 & $18 / 8,4$ & $\begin{array}{l}\text { Annular hypoplasia, supra-valvular } \\
\text { ring }\end{array}$ & 12 & 7 & Resection of supra-valvular ring & $\begin{array}{l}\text { DORV repair, } \\
\text { pulmonary debanding }\end{array}$ & Re-repair \\
\hline 13 & $19 / 5,5$ & Shone, parachute & 18 & 12 & $\begin{array}{l}\text { Commissurotomy, splitting } \\
\text { papillary muscle }\end{array}$ & $\begin{array}{l}\text { Subaortic stenosis, } \\
\text { tricuspid valve repair }\end{array}$ & Replacement \\
\hline 14 & $23,5 / 13$ & $\begin{array}{l}\text { Parachute, tethering of the leaflet to } \\
\text { the papillary muscle }\end{array}$ & 23 & 11 & $\begin{array}{l}\text { Commissurotomy, splitting } \\
\text { papillary muscle, division of } \\
\text { chords }\end{array}$ & - & - \\
\hline 15 & $25 / 9,2$ & Shone, supra-valvular ring & 24 & 11 & Resection of supra-valvular ring & $\begin{array}{l}\text { VSD closure, } \\
\text { pulmonary debanding }\end{array}$ & - \\
\hline 16 & $60 / 16,2$ & Commissure fusion, Shortened chords & 14 & - & Replacement: mp $21 \mathrm{~mm}$ & - & Re-replacement \\
\hline 17 & $102 / 13$ & $\begin{array}{l}\text { Supra-valvular ring, chordal fusion, } \\
\text { enlarged papillary muscle }\end{array}$ & 17 & 16 & $\begin{array}{l}\text { Resection of supra-valvular ring, } \\
\text { splitting papillary muscles, } \\
\text { division of chordae, posterior left } \\
\text { atrium wall plicature }\end{array}$ & Subaortic resection & - \\
\hline 18 & $112 / 24,5$ & Commissure fusion, shortened chordae & 30 & 28 & Replacement: mp 25 mm & - & - \\
\hline 19 & $117 / 26,3$ & $\begin{array}{l}\text { Commissure fusion, thickened } \\
\text { leaflets }\end{array}$ & 25 & 23 & Replacement: mp $23 \mathrm{~mm}$ & $\begin{array}{l}\text { Supra-valvar aortic } \\
\text { stenosis repair }\end{array}$ & - \\
\hline 20 & $132 / 26,5$ & $\begin{array}{l}\text { Supra-valvular ring, absence of } \\
\text { chordae, papillary muscle } \\
\text { elongation }\end{array}$ & 8,5 & 21 & $\begin{array}{l}\text { Resection of supra-valvular } \\
\text { ring, splitting papillary } \\
\text { muscles, remodeling posterior } \\
\text { wall left atrium }\end{array}$ & - & - \\
\hline 21 & $135 / 36$ & $\begin{array}{l}\text { Commissure fusion, thickened } \\
\text { leaflets }\end{array}$ & 9 & 24 & Commissurotomy & Aortic valve repair & - \\
\hline 22 & $156 / 30,5$ & Commissure fusion, shortened chordae & 9,5 & 22 & $\begin{array}{l}\text { Commissurotomy, splitting } \\
\text { papillary muscles }\end{array}$ & - & - \\
\hline 23 & $204 / 51,6$ & Papillary muscle hypoplasia & 16 & 25 & Replacement: mp $25 \mathrm{~mm}$ & - & - \\
\hline
\end{tabular}


predictors of durability of repair. The level of statistical significance considered was less than 5\%. Freedom from reoperation in the follow-up was calculated by the KaplanMeier method.

\section{RESULTS}

There were no early or late deaths. The mean hospital stay was $12.7 \pm 8.2$ days. One patient had transient heart block and another two had significant mitral regurgitation that required re-intervention due to prolonged respiratory failure. These two patients underwent mitral valve replacement with mechanical prosthesis (St Jude Medical Inc., St Paul, MN), sizes 17 and 19 millimeters. Despite having a worse overall status, with long-term intensive care stay, under mechanical ventilation and inotropic support; a new attempt of valve repair was made, before the final decision to replace their native valves.

Before discharge, two patients had moderate mitral stenosis and 10 patients mild mitral stenosis. Eight patients had associated mild mitral regurgitation. The mean postoperative trans-mitral gradient was $5.75 \pm 3 \mathrm{mmHg}$ (range $2-13 \mathrm{mmHg}$ ).

There were no predictors of failed mitral valve repair, including younger age, low body weight, parachute mitral valve, small indexed mitral annulus, presence of preoperative mitral regurgitation, inotropic support, Shone's complex, pulmonary hypertension and associated procedures.

The follow-up was completed over a mean of $58.5 \pm 46.7$ months (range 1-156 months). The actuarial freedom from reoperation (Figure 1) at 5 years was $67.1 \%$ (95\%IC: $56.8 \%$ $77.4 \%$ ). The group submitted to mitral repair required reoperations in eight patients (44.4\%), including two early and two late, compared to one (20\%) reoperation in the mitral replacement group (NS). The indication for reoperation in this latter group was functional mitral stenosis, caused by patient-prosthesis mismatch. Among the six patients that required late re-interventions in the repair group, four were successfully submitted to re-repair, although two of them had a third operation for valve replacement in a mean of 40 months later.

The same predictive factors used for the failed mitral repair were analyzed regarding the durability of mitral repair. The presence of preoperative pulmonary hypertension was considered statistically $(\mathrm{p}<0.005)$ associated to higher reoperation rates. All the other factors did not show significance to the need for reoperations. There was no statistical correlation between pulmonary hypertension, parachute mitral valve and Shone's complex.

Twenty-one patients $(91.3 \%)$ ) are in functional class I of NYHA and the echocardiography showed less than mild mitral stenosis and/or regurgitation. The other two patients have been compensated with medical treatment for congestive heart failure. The most recent echocardiography showed moderate mitral stenosis and regurgitation in one (mean trans-mitral gradient of $22 \mathrm{mmHg}$ ). This patient (patient 6 -table 5) is awaiting a new operation. The other patient (patient 5-table 5) underwent a 17-millimeter mechanical valve replacement, and is currently in functional class II of NYHA, clinically stable, and the mitral stenosis is considered moderate. This patient is being followed-up, and there is a strong probability of a second valve replacement in the medium-term.

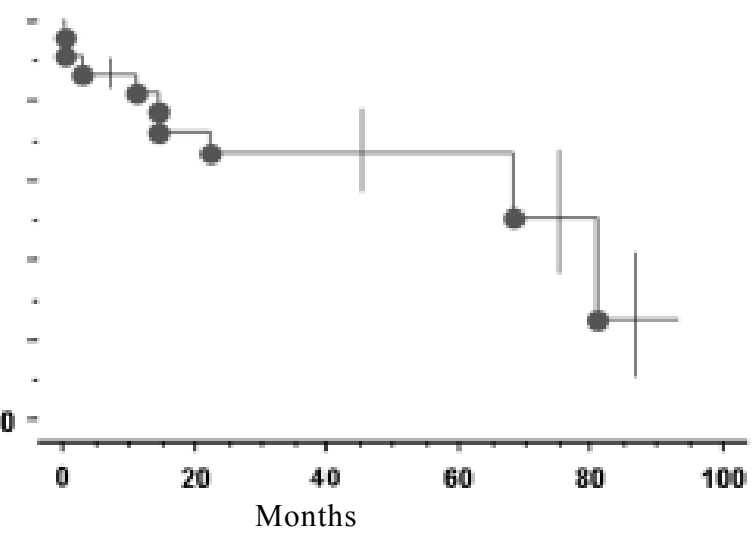

Fig. 1 - Actuarial freedom from reoperation in congenital mitral stenosis according to the Kaplan-Meier method

All patients have been under oral anticoagulation treatment, aiming at an INR between 2.5 and 3.5. Minor anticoagulation related complications occurred in two patients. There were no documented episodes of endocarditis or thromboembolism.

\section{DISCUSSION}

The surgical treatment of CMS is usually postponed in the neonatal period until the symptoms appear. A higher surgical risk is closely related to unfavorable anatomical features. An efficient and durable repair is somewhat difficult to achieve due to limited exposure of the valvar and subvalvar apparatus in small structured hearts. Furthermore, there is a fear of implanting a prosthesis whose diameter is bigger than the native valvular annulus. Unfortunately, the operation is mandatory when there are signs of pulmonary hypertension, due to its progressive and lethal natural history [12]. This is especially true in patients with multiple level left heart obstructive lesions, which constitute the most frequent associated anomalies[2, 11, 13]. The strategy of repairing all the anomalies in the same procedure, even the more complex, was associated to better postoperative recovery and more favorable outcome [11]. The protocol of 
our service is to treat the coarctation of aorta before the mitral stenosis, which is postponed as long as possible, in order to minimize the operative risk, as defended by others authors $[14,15]$. In this context, all intracardiac anomalies would be corrected in the same procedure.

A successful operation for CMS is characterized by a good functional result rather than an expressive anatomical reconstruction [13]. The goals are to relieve the inlet obstruction of the left ventricle and not to create or worsen the valve competence. Many times, this objective is accomplished through minimal procedures, such as resection of isolated supra-valvular ring [12]. Due to a great variability of pathologic presentations, the preferred surgical strategy has not been defined. Meanwhile, the mitral valve morphology is the most relevant aspect to be considered in the surgical planning [16].

CMS represents a spectrum of anomalies that involve in isolation or in combination the valve annulus, leaflets, chordae and the papillary muscles. The typical form described by RUCKMAN and VAN PRAAGH [2] is defined by shortened chordae, loss of interpapillary distance and leaflet implantation defects. The more severe forms are those with abnormalities of the papillary muscles according to CARPENTIER et al. [8], resulting in more difficult valve reparative procedures. Parachute mitral valve is the most frequent form of this subgroup, associated or not to Shone's complex. Its hallmark is the presence of a single papillary muscle, fixed to the posterolateral wall of the left ventricle, with obliteration of the space between the chords. In some severe forms, there is amputation of the ventricular apex, depending on the degree of myocardial hypertrophy. Focal areas of endocardial fibrosis can be observed. The operation consists of splitting or fenestration of the papillary muscle, with division of chords in correspondence to the leaflets, associated or not to commissurotomy. In order to maintain the valve competence, it is essential to fenestrate very meticulously the papillary muscle. Furthermore, division of chordae is considered important in maintaining the leaflet support.

Hammock mitral valve is considered the most difficult form in terms of valve repair. It is characterized by severe valve dysplasia and the presence of severe muscular hypertrophy that usually obliterates the inlet of the left ventricle. Valve chordae are usually absent and there is fusion of both papillary muscles and the leaflets, where the commissures are supposed to be. Viewing from the atrium, it looks like a funnel. There is a big and single leaflet, with a tiny central orifice and undetectable commissures. Arcade mitral valve is considered a variant of the aforementioned form. The particularity is the presence of a single muscular arcade with shortened chords, instead of two well-formed papillary muscles.
Identification of all components of mitral valve disease is very important in the surgical planning, because usually there are several mechanisms in the same patient. The resection of the supra-valvular ring may hide other stenotic lesions in the valvar and subvalvar regions [5], as demonstrated in three patients of our series with coexistent parachute mitral valve. BANERJEE et al. [17] found supravalvular rings in $71 \%$ of patients with parachute mitral valve, in comparison to $19 \%$ of patients with two well-formed papillary muscles.

In this context, surgical exposure of the mitral valve is essential. An inadequate exposure can adversely affect the valve repair, leading to higher replacement rates. This is especially true in patients with abnormalities of the subvalvar apparatus. In this instance, reduced dimensions of the left atrium and mitral annulus, and frequent fusion of the commissures hamper exposure [18]. Based on these limitations, BARBERO-MARCIAL et al. [18] proposed the apical left ventriculotomy as a surgical approach to the mitral valve. The early results were excellent, in accordance to others [19]. Potential problems should be investigated in the long-term follow-up, especially left ventricular dysfunction and propensity to arrhythmias. In our study, the preferential access to the mitral valve was the interatrial septum in $69.6 \%$ of patients. Using this approach, exposure was considered satisfactory with a $70 \%$ valve repair rate and no mortality.

The superiority of valve repair in relation to replacement is unnecessary to mention, especially in the pediatric population [20]. Nevertheless, there are specific situations that require valve replacement, such as severely dysplastic valves, with lack of valvar tissue (leaflets and chordae) and papillary muscle deformities.

On the other hand, valve replacement should be reserved as the last resort. The surgeon must be extremely meticulous in order to get the best possible surgical relief of the stenosis without replacing the valve. Sometimes, the decision of accepting a residual defect demands a more prolonged and difficult postoperative recovery. In this situation, follow-up has to be strictly observed, keeping in mind the inevitable recurrence of symptoms, which usually are the indication for a new operation. Actually, some of our patients, especially those with very dysplastic valves, experienced residual lesions after the surgical procedure. These patients were followed closely, and they are clinically compensated. So far the ventricular function and diameters are preserved, but the new operation is delayed as much as possible due to the almost inevitable need of valve replacement. In this instance, re-repair never should be discarded, which was performed in four of six patients in our experience. 
Recent series in the literature have showed the safety of valve repair in most of the patients with CMS [8]. The hospital mortality $[10,11,18,21,22]$ progressively improved, between zero and $12.5 \%$. SERRAF et al. [11] identified as independent predictors of mortality the staged procedure for associated anomalies and the presence of left ventricular outflow tract obstruction. Other important factors were age less than three months, Shone's complex, pulmonary hypertension and small valve annulus. PRIFTI et al. [22] considered the presence of associated anomalies and Hammock mitral valve as risk factors for hospital mortality, as opposed to others $[4,21]$ who believe that pulmonary hypertension and myocardial dysfunction were the most relevant ones.

Reoperations constitute the major problem in the medium- and long-term follow-up. In 72 patients studied by SERRAF et al.[11], freedom from reoperation and freedom from valve replacement at 10 years were 58\% and $69 \%$, respectively. These authors did not find any specific predictors of need for reoperation. Others $[10,23]$ showed less encouraging results, postulating that the high reoperation rate would be related to the complexity of the valve disease and the presence of associated anomalies [10]. In our experience, the single factor related to higher reoperation rate was preoperative pulmonary hypertension.

Shone's complex is a special subset of patients, with worse outcomes $[14,15]$. The classical form includes four different components which unusually coexist: supravalvular mitral ring, parachute mitral valve, subaortic stenosis and coarctation of aorta. Those patients represent severe forms of mitral disease and left ventricular outflow tract obstruction, frequently associated to some degree of pulmonary hypertension [14]. Although not statistically significant in this paper, the relationship between Shone's complex and pulmonary hypertension is completely understandable, due to more intense multi-level left obstructive lesions. These patients usually have high reoperation rates, related to residual mitral stenosis, as well as subaortic stenosis.

Limitations of this study include the small number of patients and wide range of anatomical forms, which might have an effect on the statistical analysis.

\section{CONCLUSIONS}

Reoperations were the most frequent problem in the medium-term follow-up after CMS. Pulmonary hypertension may predict the need for reoperation after mitral valve repair, which is the treatment of choice in CMS

\section{REFERÊNCIAS BIBLIOGRÁFICAS}

1. Keith J, Rowe R, Vlad P. Mitral stenosis. In: Heart disease in infants, children and adolescents. New York: MacMillian; 1967. p. 883-93.

2. Ruckman RN, Van Praagh R. Anatomic types of congenital mitral stenosis: report of 49 autopsy cases with consideration of diagnosis and surgical implications. Am J Cardiol 1978; 42:592-601.

3. Shone JD, Sellers RD, Anderson RC, Adams Jr. P, Lillehei CW, Edwards JE. The developmental complex of "parachute mitral valve", supravalvular ring of left atrium, subaortic stenosis and coarctation of aorta. Am J Cardiol 1963; 11:714-25.

4. Chauvaud S, Fuzellier JF, Houel R, Berrebi A, Mihaileanu S, Carpentier A. Reconstructive surgery in congenital mitral valve insufficiency (Carpentier's techniques): long-term results. J Thorac Cardiovasc Surg 1998; 115:84-93.

5. Zias EA, Mavroudis C, Backer CL, Kohr LM, Gotteiner NL, Rocchini AP. Surgical repair of the congenitally malformed mitral valve in infants and children. Ann Thorac Surg 1998; 66:1551-9.

6. Waldhausen JA, Nahrwold DL. Repair of coarctation of the aorta with a subclavian flap. J Thorac Cardiovasc Surg 1966; 51:532-3.

7. Herman TE, Siegel MJ. VACTERL-H syndrome. J Perinatol $2002 ; 22: 496-8$

8. Carpentier A, Branchini B, Cour JC, Asfaou E, Villani M, Deloche A et al. Congenital malformations of the mitral valve in children: pathology and surgical treatment. J Thorac Cardiovasc Surg 1976; 72:854-66.

9. Reddy VM, Rajasinghe HA, Teitel DF, Haas GS, Hanley FL. Aortoventriculoplasty with the pulmonary autograft: the "RossKonno" procedure. J Thorac Cardiovasc Surg 1996; 111:158-67.

10. Sousa Uva M, Galletti L, Lacour-Gayet F, Piot D, Serraf A, Bruniaux J et al. Surgery for congenital mitral valve disease in the first year of life. J Thorac Cardiovasc Surg 1995; 109:164-76

11. Serraf A, Zoghbi J, Belli E, Lacour-Gayet F, Aznag H, Houyel $\mathrm{L}$ et al. Congenital mitral stenosis with or without associated defects: an evolving surgical strategy. Circulation 2000; 102:III166-71

12. Sullivan ID, Robinson PJ, de Leval M, Graham Jr. TP. Membranous supravalvular mitral stenosis: a treatable form of congenital heart disease. J Am Coll Cardiol 1986; 8:159-64.

13. Stellin G, Padalino M, Milanesi O, Vida V, Favaro A, Rubino $\mathrm{M}$ et al. Repair of congenital mitral valve dysplasia in infants and children: is it always possible? Eur J Cardiothorac Surg $2000 ; 18: 74-82$. 
14. Bolling SF, Iannettoni MD, Dick $2^{\text {nd }} \mathrm{M}$, Rosenthal A, Bove EL. Shone's anomaly: operative results and late outcome. Ann Thorac Surg 1990; 49:887-93.

15. Brauner RA, Laks H, Drinkwater Jr. DC, Scholl F, McCaffery S. Multiple left heart obstructions (Shone's anomaly) with mitral valve involvement: long-term surgical outcome. Ann Thorac Surg 1997; 64:721-9.

16. Mitruka SN, Lamberti JJ. Congenital Heart Surgery Nomenclature and Database Project: mitral valve disease. Ann Thorac Surg 2000; 69:S132-46.

17. Banerjee A, Kohl T, Silverman NH. Echocardiographic evaluation of congenital mitral valve anomalies in children. Am J Cardiol 1995; 76:1284-91.

18. Barbero-Marcial M, Riso A, Albuquerque AT, Atik E, Jatene A. Left ventricular apical approach for the surgical treatment of congenital mitral stenosis. J Thorac Cardiovasc Surg 1993 106:105-10.
19. Inaba H, Furuse A, Kubota H, Kotsuka Y, Yagyu K, Kawauchi M. Mitral valve repair through combined left atrial and ventricular approach for congenital mitral stenosis. Thorac Cardiovasc Surg 1997; 45:313-5.

20. Gunther T, Mazzitelli D, Schreiber C, Wottke M, Paek SU, Meisner $\mathrm{H}$ et al. Mitral valve replacement in children under 6 years of age. Eur J Cardiothorac Surg 2000; 17:426-30.

21. Yoshimura N, Yamaguchi M, Oshima Y, Oka S, Oataki Y, Murakami $\mathrm{H}$ et al. Surgery for mitral valve disease in the pediatric age group. J Thorac Cardiovasc Surg 1999; 118:99106.

22. Prifti E, Vanini V, Bonacchi M, Frati G, Bernabei M, Giunti G et al. Repair of congenital malformations of the mitral valve: early and midterm results. Ann Thorac Surg 2002; 73:614-21.

23. Lorier G, Kalil RA, Barcellos C, Teleo N, Hoppen GR, Netto $\mathrm{AH}$ et al. Valve repair in children with congenital mitral lesions: late clinical results. Pediatr Cardiol 2001; 22:44-52. 